\title{
Adolescent development of psychosis as an outcome of hearing impairment: a 10-year longitudinal study
}

\author{
M. van der Werf ${ }^{1 *}$, V. Thewissen ${ }^{1,2}$, M. D. Dominguez ${ }^{1}$, R. Lieb ${ }^{3,4}$, H. Wittchen ${ }^{3,5}$ and J. van Os ${ }^{1,6}$ \\ ${ }^{1}$ Department of Psychiatry and Neuropsychology, South Limburg Mental Health Research and Teaching Network, EURON Graduate School of \\ Neuroscience, Maastricht University Medical Centre, Maastricht, The Netherlands \\ ${ }^{2}$ Open University of the Netherlands, Faculty of Psychology, Heerlen, The Netherlands \\ ${ }^{3}$ Max Planck Institute of Psychiatry, Clinical Psychology and Epidemiology Unit, Munich, Germany \\ ${ }^{4}$ Epidemiology and Health Psychology, Institute of Psychology, University of Basel, Basel, Switzerland \\ ${ }^{5}$ Institute of Clinical Psychology and Psychotherapy, Technical University Dresden, Dresden, Germany \\ ${ }^{6}$ King's College London, King's Health Partners, Department of Psychosis Studies, Institute of Psychiatry, London, UK
}

Background. It has long been acknowledged that hearing impairment may increase the risk for psychotic experiences. Recent work suggests that young people in particular may be at risk, indicating a possible developmental mechanism.

Method. The hypothesis that individuals exposed to hearing impairment in early adolescence would display the highest risk for psychotic symptoms was examined in a prospective cohort study of a population sample of originally 3021 adolescents and young adults aged 14-24 years at baseline, in Munich, Germany (Early Developmental Stages of Psychopathology Study). The expression of psychosis was assessed at multiple time points over a period of up to 10 years, using a diagnostic interview (Munich Composite International Diagnostic Interview; CIDI) administered by clinical psychologists.

Results. Hearing impairment was associated with CIDI psychotic symptoms [odds ratio (OR) 2.04, 95\% confidence interval (CI) 1.10-3.81], particularly more severe psychotic symptoms (OR 5.66, 95\% CI 1.64-19.49). The association between hearing impairment and CIDI psychotic symptoms was much stronger in the youngest group aged 14-17 years at baseline (OR 3.28, 95\% CI 1.54-7.01) than in the older group aged 18-24 years at baseline (OR 0.82, 95\% CI 0.24-2.84).

Conclusions. The finding of an age-specific association between hearing impairment and psychotic experiences suggests that disruption of development at a critical adolescent phase, in interaction with other personal and social vulnerabilities, may increase the risk for psychotic symptoms.

Received 2 October 2009; Revised 10 March 2010; Accepted 6 April 2010; First published online 19 May 2010

Key words: Adolescents, development, hearing impairment, psychosis, social cognition.

\section{Introduction}

Recent meta-analyses of general population surveys suggest that psychometric liability for psychosis in the form of subclinical psychotic experiences, such as paranoid delusional thinking and fleeting auditory hallucinations, is present in $5-10 \%$ of healthy people (van Os et al. 2009; Linscott \& van Os, 2010). There is consistent evidence that the highest rates are observed in adolecents and young adults (Verdoux et al. 1998; Peters et al. 1999; Rossler et al. 2007; Lataster et al.

\footnotetext{
* Address for correspondence: M. van der Werf, Department of Psychiatry and Neuropsychology, Maastricht University Medical Centre, PO Box 616 (VIJV), 6200 MD Maastricht, The Netherlands.

(Email: m.vanderwerf@sp.unimaas.nl)
}

2009). Follow-up studies indicate that the majority of low-grade psychotic phenomena are benign and transitory (Hanssen et al. 2005; Cougnard et al. 2007). However, there is evidence from two birth cohorts (Poulton et al. 2000; Welham et al. 2009), three representative general population cohorts (Hanssen et al. 2005; Dominguez et al. 2009; Weiser et al. 2009) and other longitudinal work (Chapman et al. 1994) that low-grade psychotic experiences such as delusional thinking and mild hallucinatory experiences may precede the diagnosis of psychotic disorder and hospital admission for schizophrenia by many years. It has been suggested that environmental risk factors operating in early adolescence may interact with background genetic risk (van Os et al. 2008) in producing low-grade delusional ideation and 


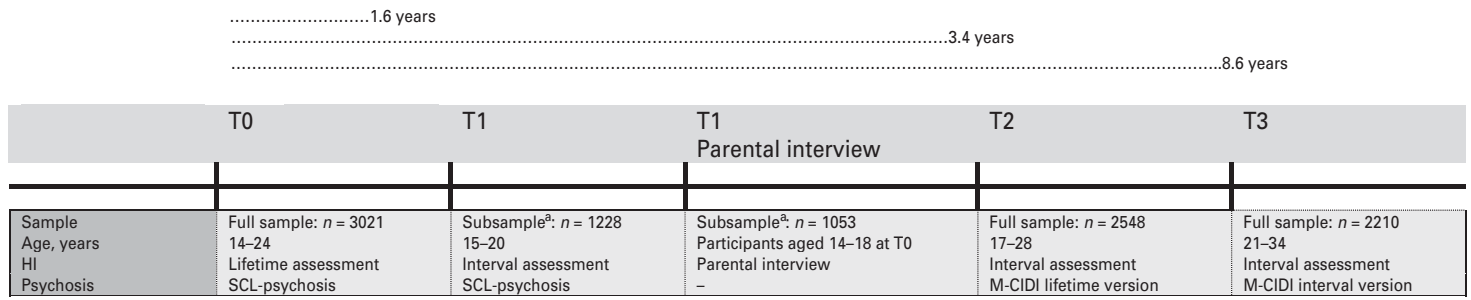

Fig. 1. Design of the Early Developmental Stages of Psychopathology Study. The time-line shows the assessments at each time point. ${ }^{\text {a }}$ The subsample of participants aged 14-17 years at baseline. For 1053 of these, parental interviews were completed. Parental reports of childhood hearing impairment (HI) were available for 723 participants. T0, Time 0 (baseline investigation); T1, time 1 (follow-up investigation 1); T2, time 2 (follow-up investigation 2); T3, time 3 (follow-up investigation 3); SCL, self-report Symptom Checklist; M-CIDI, Munich Composite International Diagnostic Interview.

hallucinatory experiences that in some cases, if persistent, may progress to full-blown clinical psychotic states (Dominguez et al. 2009; Kaymaz \& van Os, 2010).

There is evidence suggesting that hearing impairment (HI) increases the risk for psychosis (Stefanis et al. 2006; van der Werf et al. 2007), particularly in young people (David et al. 1995; Thewissen et al. 2005). Although the mechanism by which HI may increase risk for psychosis in young people remains elusive, a number of hypotheses have been put forward. First, $\mathrm{HI}$ and psychosis may be the consequence of a common underlying cause. For example, exposure to perinatal infections affecting the central nervous system, such as rubella and meningitis (Brown et al. 2000; Leask et al. 2002; Dalman et al. 2008), may explain the association between early $\mathrm{HI}$ and later psychosis. Second, psychotic experiences may be a direct or indirect consequence of processes triggered by hearing loss. For example, experimental studies have demonstrated psychotomimetic effects induced by sensory deprivation (Leff, 1968; Mason \& Brady, 2009). In addition, it has been proposed that hearing loss may indirectly increase psychosis risk through social defeat stress (Selten \& Cantor-Graae, 2007). Finally, HI originating early in life may have an impact on risk for psychosis by interfering with critical developmental phases for language, cognition and social skills (Bess et al. 1998).

The current investigation focused on the expression of psychosis in adolescents with HI. It was hypothesized that adolescent HI, particularly in the phase of early adolescence, would be associated with an increased risk for psychotic symptoms. We relied on assessments of psychotic experiences by trained and experienced clinical psychologists in order to reduce the risk of false positive ratings. In addition, the longitudinal design allowed for the examination of possible alterations in exposure assessment induced by high levels of psychosis proneness at baseline.

\section{Method}

\section{Sample and study design}

The Early Developmental Stages of Psychopathology (EDSP) Study is a prospective longitudinal cohort community study which collected data on the prevalence, incidence, risk factors and course of mental disorders. Following ethics committee approval, the sample was randomly drawn from the 1994 government population registers. The sample consisted of adolescent and young adults living in the Munich area (Germany), aged 14 to 24 years at baseline. Participants completed a baseline investigation (T0) and three follow-up investigations (T1, T2 and T3). At baseline, 3021 interviews were completed (response rate: $71 \%$ ). Because the study primarily intended to examine the incidence and developmental risk factors for psychopathology, the younger group (14-15 years) was sampled at twice the rate of persons aged 16-21 years, and the oldest group (22-24 years) was sampled at half this rate. Furthermore, participants aged 14-17 years were assessed three times (T1, T2, T3) and participants aged 18-24 years were assessed only two times (T2, T3) after baseline. The follow-up periods had mean durations of approximately 1.6 years $(\mathrm{T} 0-\mathrm{T} 1$, S.D. $=0.2), 3.4$ years $(\mathrm{T} 0-\mathrm{T} 2$, S.D. $=0.3)$ and 8.6 years $(\mathrm{T} 0-\mathrm{T} 3$, range $7.4-10.6$ years, S.D. $=0.7)$. The risk set consisted of the 3021 individuals at baseline and their $\mathrm{T} 1(n=1228$, response rate $=88 \%), \mathrm{T} 2(n=$ 2548 , response rate $=84 \%)$ and T3 $(n=2210$, response rate $=73 \%$ ) follow-up measurements. Fig. 1 shows an overview of the study design and lists the measurements conducted at the different time points. Written informed consent was obtained from all participants. More detailed information about the EDSP Study can 
be found elsewhere (Wittchen et al. 1998b; Lieb et al. 2000).

\section{Instruments}

\section{Assessment of psychotic experiences}

Psychotic experiences were assessed using the computer-assisted version of the Munich Composite International Diagnostic Interview (DIA-X/M-CIDI) (Wittchen \& Pfister, 1997), an updated version of the World Health Organization's CIDI version 1.2 (WHO, 1990). The DIA-X/M-CIDI is a comprehensive, fully standardized computer-assisted diagnostic interview for the assessment of symptoms, syndromes and diagnoses of various mental disorders in accordance with the Diagnostic and Statistical Manual of Mental Disorders, 4th edition (DSM-IV) criteria, along with information about psychosocial impairment as well as the onset, duration and severity of symptoms. The DIA-X/M-CIDI was developed specifically for use in adolescents and young adults. High validity (Reed et al. 1998) and high inter-rater and test-retest reliability of the CIDI have previously been shown (Wittchen, 1994; Wittchen et al. 1998a). Fully trained and experienced clinical psychologists, who were allowed to probe with clinical follow-up questions, conducted the interviews to ensure validity and reliability of assessments. The lifetime version of the DIA-X/M-CIDI was used at baseline and the interval version was applied at each of the follow-ups, covering the respective time periods between interviews.

The presence of psychotic experiences was assessed using the 20 core psychosis items of the DIA-X/MCIDI-G section (G1, G2a, G3-G5, G7-G13, G13b, G14, G17, G18, G20, G20c, G21 and G22a) including symptoms of delusions, hallucinations and passivity phenomena. Participants first read a list of all the psychotic experiences and were then asked whether they ever experienced these symptoms (list and phrasing available upon request). All items could be rated as absent or present, without intermediate levels. Data on the DIA-X/M-CIDI-psychosis section were collected at T2 (lifetime version) and T3 (interval version) only. The mean interval between T2 and T3 measurements was 4.9 years. Two different outcome measures were created: (i) a dichotomous variable indicating the presence or absence of at least one positive rating on the 20 core psychotic items (hereafter: CIDI-psychosis) and (ii) in order to examine doseresponse in the association between $\mathrm{HI}$ and psychotic experiences at increasing levels of psychosis severity, four progressively stricter psychosis subcategories were constructed (hereafter: CIDI-psychosis severity) with: no symptoms (0), one or two symptoms
(1), three or four symptoms (2) and at least five symptoms (3).

In addition, participants completed the self-report Symptom Checklist-90-Revised at T0 (SCL-90-R; Derogatis, 1983). The SCL-90-R is a multidimensional self-report symptom inventory that assesses psychopathology as a continuous dimension of human experiences and enables screening of nine dimensions of psychopathology (Derogatis, 1983; Arrindell \& Ettema, 2003). Reliability and validity have been established previously (Bonicatto et al. 1997). Baseline psychosis proneness was assessed using the paranoid ideation (six items) and psychoticism (10 items) subscales. These subscales include self-reports on psychotic experiences that can be regarded, if not as clear-cut psychotic symptoms, as an expression of psychosis proneness. In accordance with previous analyses in this sample (Henquet et al. 2005), the total scores of both subscales were combined into a single dimension reflecting psychotic experiences. In line with previous work (Henquet et al. 2005), and as validated recently (Dominguez et al. 2009), baseline psychosis proneness was defined dichotomously as the group of participants with the highest $10 \%$ of scores (hereafter: SCL-psychosis).

\section{T0-T3 assessment of HI}

The presence of HI was based on self-report and assessed at T0 (lifetime assessment) and over the T0-T1, T1-T2 and T2-T3 intervals (interval assessments). The assessment was included in a questionnaire enquiring about a range of somatic complaints, including sensory deficits. At T0, participants were asked the following question: 'Did you ever experience a period in which you were unable to hear anything at all?', yielding a binary exposure variable. At the T1, T2 and T3 follow-ups, HI was assessed using the same question, restricted to the interval since the last interview. Since complete deafness was an exclusion criterion for EDSP study participation at baseline, the impairment assessed referred to a period of transient or permanent severe HI. The most common causes of severe hearing loss that may temporarily or permanently affect young people include syndromal or non-syndromal genetic disorders, prenatal and perinatal infections and noise exposure (for reviews, see Olusanya \& Newton, 2007; Tharpe \& Sladen, 2008).

\section{Childhood HI}

Although previous work suggests that selfreported HI has adequate sensitivity and specificity (Sindhusake et al. 2001), an additional parental indicator of childhood HI was used to validate the exposure of $\mathrm{HI}$ in the current study. A parental 
investigation was conducted at $\mathrm{T} 1$ in the subsample of participants aged 14-17 years at baseline $(n=$ 1053). Using a standardized checklist (Wittchen et al. 1999), information was gathered about family and early childhood variables, including sensory deficits. Parental reports of childhood HI, rated dichotomously, were available for 723 participants.

\section{Statistical analysis}

All analyses were conducted in Stata, version 10 (StataCorp., USA). Prevalence estimates of $\mathrm{HI}$ and cumulative lifetime incidence of CIDI-psychosis were calculated. As data were acquired at multiple points in time, associations between exposure and outcome were analysed with data in the long format, i.e. each individual in the study contributed multiple observations (the variable 'time' expressing the number of measurements for each person, with a maximum of four measurements at T0, T1, T2 and T3). Clustering of observations within subjects was controlled for by adjusting for the variable 'time' in the model. Based on previous work, all analyses were adjusted for sex, age at baseline and education (low, medium, high). As young people may acquire hearing loss at a young age by attending pop concerts, during which exposure to illicit drugs may also occur, analyses were additionally adjusted for use of any illicit drugs at baseline (including cannabis, amphetamine, cocaine and other stimulants) at least five times lifetime (' 0 ' no, ' 1 ' yes).

\section{Association between HI and psychotic experiences at $\mathrm{T} 2$ and $\mathrm{T} 3$}

The association between HI and CIDI-psychosis at T2 and T3 was examined by logistic regression analysis, with associations expressed as odds ratios (ORs) and their corresponding 95\% confidence intervals (CIs). In order to exclude the possibility that any association between $\mathrm{HI}$ and psychotic symptoms would be confounded by high levels of baseline psychosis proneness (given that this measure may possibly be associated with over-reporting of $\mathrm{HI}$ and, independent of that, with psychotic symptoms at follow-up), analyses of association between HI and T2-T3 CIDIpsychosis were repeated with additional adjustment for T0 SCL-psychosis. In addition, analyses were also repeated on a subsample from which participants with the $50 \%$ highest baseline SCL-psychosis scores were excluded. Finally, as previous research has shown that the effect of certain predictors of psychosis [e.g. cannabis (Henquet et al. 2005) and childhood trauma (Spauwen et al. 2006)] is stronger in individuals already showing some degree of psychosis proneness at baseline, we examined whether the association between HI and T2-T3 CIDI-psychosis was stronger in those with higher levels of baseline psychosis proneness. To this end, a $\mathrm{HI} \times$ baseline SCL-psychosis interaction term was included in the model.

\section{Associations at different levels of psychosis severity}

The magnitude of the association between $\mathrm{HI}$ and different levels of psychosis severity was examined using multinomial logistic regression with the Stata MLOGIT routine, with the lowest psychosis-severity subcategory serving as the reference group.

\section{Age-dependent association}

The hypothesized age-dependent association between $\mathrm{HI}$ and psychosis was tested by splitting the baseline sample around the median age, creating a young (14-17 years) and an old (18-24 years) age group. An age $\times \mathrm{HI}$ interaction term was fitted followed by calculation of age-stratified effects from the model including the interaction by applying the appropriate linear combinations using the Stata LINCOM routine.

\section{Childhood HI}

In order to validate the self-report measure of $\mathrm{HI}$ used in the current study, the association between childhood HI (based on parental report; see Fig. 1), and T0 HI (which should include any childhood experience of $\mathrm{HI}$ ) was assessed by logistic regression analysis. In addition, the association between childhood $\mathrm{HI}$ and baseline SCL-psychosis was examined using logistic regression analysis. Finally, the association between $\mathrm{HI}$ and CIDI-psychosis was examined after excluding all individuals with $\mathrm{HI}$ whose parents had not reported a similar impairment during childhood.

\section{Results}

Mean age at baseline was 18.3 years (s.D. $=3.3$ ) and $49.3 \%$ were male. The cumulative lifetime incidence of CIDI-psychosis at T3 was $17.9 \%(n=848)$. The prevalence of $\mathrm{HI}$ over time was: $\mathrm{T} 0=92(3.1 \%), \mathrm{T} 1=8$ $(0.7 \%), \mathrm{T} 2=18(0.8 \%)$ and $\mathrm{T} 3=33(1.6 \%)$, yielding a total of 151 (1.8\%) observations of HI. Of the subjects, seven reported $\mathrm{HI}$ at two time points and one at three time points. Neither CIDI-psychosis (OR 0.99, 95\% CI 0.97-1.01) nor HI (OR 1.04, 95\% CI 0.99-1.09) were associated with age.

\section{Association between $\mathrm{HI}$ and psychotic experiences at T2-T3}

There were 47 participants who reported $\mathrm{HI}$ at either $\mathrm{T} 2$ or T3, and two participants who reported $\mathrm{HI}$ at both T2 and T3, yielding a total of 51 observations of $\mathrm{HI}$ in 
Table 1. Associations between cumulative lifetime incidence of hearing impairment (time points T0 to T3) and psychotic symptoms (CIDI-psychosis) at different levels of severity

\begin{tabular}{llllll}
\hline & & $\begin{array}{l}\text { Hearing } \\
\text { impairment } \\
n^{\mathrm{a}}(\%)\end{array}$ & $\begin{array}{l}\text { No hearing } \\
\text { impairment } \\
n^{\mathrm{a}}(\%)\end{array}$ & $\begin{array}{l}\text { Unadjusted } \\
\text { model } \\
\text { RR }(95 \% \text { CI })\end{array}$ & $\begin{array}{l}\text { Adjusted } \\
\text { model }^{\mathrm{b}} \\
\text { RR (95\% CI) }\end{array}$ \\
\hline Severity level & No symptoms & $36(70.6)$ & $3543(81.7)$ & - & - \\
& $1-2$ symptoms & $8(15.7)$ & $623(14.4)$ & $1.46(0.67-3.18)$ & $1.41(0.65-3.08)$ \\
& 3-4 symptoms & $4(7.8)$ & $116(2.7)$ & $4.14(1.43-11.98)$ & $3.82(1.31-11.17)$ \\
& 5 or more symptoms & $3(5.9)$ & $56(1.3)$ & $6.33(1.87-21.41)$ & $5.66(1.64-19.49)$ \\
\hline
\end{tabular}

T0, Time 0 (baseline investigation); T3, time 3 (follow-up investigation 3); CIDI, Composite International Diagnostic Interview ; RR, relative risk; CI, confidence interval.

a $n$ Refers to multiple observations clustered in individuals.

${ }^{\mathrm{b}}$ Adjusted for sex, education, drug abuse and time.

${ }^{\mathrm{c}}$ Reference category.

the combined T2-T3 assessments. The association between HI and CIDI-psychosis was significant (OR 2.16, 95\% CI 1.17-4.01). Adjustment for age, sex, education and drug abuse (OR 2.04, 95\% CI 1.10-3.81) and baseline SCL-psychosis (OR 1.99, 95\% CI 1.06-3.73) did not attenuate the association.

The magnitude of the association with $\mathrm{HI}$ increased with increasing levels of CIDI-psychosis severity (Table 1). A negative interaction between $\mathrm{HI}$ and age was apparent in the model of CIDI-psychosis $\left(\chi^{2}=5.86, p=0.016\right)$. Stratified analyses indicated that the association was strong in young (age 14-17 years: OR 3.28, 95\% CI 1.54-7.01), but not in older participants (age 18-24 years: OR 0.82, 95\% CI 0.24-2.84). There was no evidence for moderation by baseline SCL-psychosis $\left(\chi^{2}=0.00, p=0.99\right)$. Finally, the association remained large and significant after exclusion of participants with the $50 \%$ highest SCL-psychosis scores at baseline (OR 4.15, 95\% CI 1.25-13.82).

\section{Childhood HI}

In the subsample with parental reports of childhood HI $(n=723), 36$ participants were rated positive for childhood HI (5.0\%). Childhood HI was strongly associated with the T0 self-report of HI (OR 13.08, 95\% CI 4.79-35.67). In addition, childhood HI was strongly associated with the continuous baseline SCLpsychosis score (adjusted $b=2.15,95 \%$ CI 0.26-4.03). Finally, the adjusted OR for the association between $\mathrm{HI}$ and CIDI-psychosis, excluding individuals with a self-report of $\mathrm{HI}$ that was not matched by parental report of childhood HI, was 5.61 (95\% CI 0.34-91.4).

\section{Discussion}

The finding of an association between $\mathrm{HI}$ and psychotic symptoms replicates earlier work (Stefanis et al. 2006; van der Werf et al. 2007). There was evidence for a dose-response relationship, as the association grew stronger with increasing levels of symptom severity. In a subsample with parental reports of childhood sensory deficits, childhood HI similarly predicted later psychotic experiences. Finally, the association was restricted to young adolescents, which is congruent with recent accounts of an age-dependent association between $\mathrm{HI}$ and psychosis (Stefanis et al. 2006; van der Werf et al. 2007). The age-dependent effect of HI suggests that disruption of development during a critical phase, in interaction with other social and personal vulnerabilities, may render an individual more susceptible to psychotic interpretations of internal and external stimuli (Kapur et al. 2005).

\section{HI and psychosis: a shared cause?}

Numerous conditions in young people may affect hearing acuity, resulting in transient or permanent impairment (for reviews, see Olusanya \& Newton, 2007; Tharpe \& Sladen, 2008). Causes of HI in young people that may also have an impact on the risk for psychotic experiences include birth trauma (Herrgard et al. 1995) and prenatal and postnatal exposure to infections (Dalman et al. 2008; Zammit et al. 2009). Rubella and meningitis may harm the developing central nervous system, and exposure has been associated with an increased risk for both hearing deficits (Fortnum \& Davis, 1993) and psychosis (Brown et al. 2000; Leask et al. 2002; Dalman et al. 2008). Thus, HI and psychosis may be the result of a single underlying causative mechanism. This hypothesis is strengthened by a study reporting that rubella increased the risk for non-affective psychotic disorder independent of HI (Brown et al. 2000). 


\section{HI and psychosis : causality?}

Not hearing what other people say may, directly or indirectly, trigger paranoid ideation and hallucinatory experiences. There is experimental evidence that sensory deprivation, mimicking profound hearing loss, induces feelings of paranoia and hallucinations (Leff, 1968; Mason \& Brady, 2009). Sensory restriction may not only produce patterns of nerve impulses that give rise to hallucinatory experiences (Schultz \& Melzack, 1991), it may also result in reality-testing failures when the input from the outside world is significantly reduced. Failures of reality testing may cause a person to misattribute internal events to an external source. This mechanism may underlie the experience of hallucinations (Leff, 1968; Bentall, 1990). Second, social adversity has been shown to mould the risk for psychosis (Boydell et al. 2004; Veling et al. 2007). HI, whether originating early in life, or acquired later in life, is associated with social isolation, low self-esteem and increased feelings of loneliness and stress (RomansClarkson et al. 1990; Bess et al. 1998; Paykel et al. 2000; Kramer et al. 2002). The adverse emotional and social consequences of $\mathrm{HI}$ may give rise to social defeat stress (Selten \& Cantor-Graae, 2007). Prolonged exposure to social defeat stress may represent an intermediate mechanism linking multiple environmental exposures to an underlying biological mechanism of psychosis (Selten \& Cantor-Graae, 2007; van Winkel et al. 2008). Thus, social defeat stress may mediate the link between $\mathrm{HI}$ and psychosis.

\section{HI and psychosis: developmental impact?}

Finally, HI with onset early in life may compromise the development of language, cognition and social skills (Bess et al. 1998), giving rise to developmental alterations as observed in children destined to develop psychotic symptoms later in life (Cannon et al. 2002). Language and cognitive problems associated with $\mathrm{HI}$ may thus contribute to an increased risk in young people with a pre-existing vulnerability for psychosis. In addition, persecutory delusions and auditory hallucinations may develop as a result of delays in the acquisition of Theory of Mind (Frith, 1992; Janssen et al. 2003) in children with HI. Theory of Mind abilities normally emerge during preschool years (Peterson et al. 2005) and are highly dependent on day-to-day social interactions (Russell et al. 1998). Selective deprivation of access to these early conversations by HI during critical developmental phases may interfere with Theory of Mind acquisition. Evidence to support this notion comes from studies showing significant delays in the mastery of Theory of Mind in hardof-hearing children (Marschark, 1993; Peterson \&
Siegal, 1995, 1998). Thus, HI originating early in life may have an impact, during critical developmental phases, on language, cognition and social skills, increasing the risk for psychosis.

\section{HI and psychosis: towards a multifactorial model}

The association between $\mathrm{HI}$ and psychosis shows variation with age. Although the evidence to date suggests an increased risk in young people (David et al. 1995; Stefanis et al. 2006), the association has also been found in older people (Cooper \& Curry, 1976; Stein \& Thienhaus, 1993). This latter implies the operation of multiple mechanisms contributing to the increase in psychosis risk, with differential impact across the age span. HI with onset during critical developmental phases may have an impact on risk by delaying the development of social reasoning skills, language and cognition, whilst other mechanisms may be operating in people who acquire $\mathrm{HI}$ later in life. Considering the negative impact of $\mathrm{HI}$ on perceived quality of life, as expressed by increased feelings of loneliness and a tendency for social isolation, social defeat stress may represent a more general mechanism mediating the link between $\mathrm{HI}$ and psychosis, regardless of age. Therefore, to the degree that HI moulds risk for psychosis, it is likely to do so in combination with a range of other factors.

\section{Limitations}

Several limitations should be considered when interpreting these results. First, the study used a measure of $\mathrm{HI}$ that was based on self-report and consisted of a single question. Although this may not seem a very reliable measure, self-reports of $\mathrm{HI}$ have been found to yield reasonable sensitivity and specificity (Sindhusake et al. 2001). Also, EDSP interviewers were allowed to follow-through with follow-up questions to clarify if participants had understood the question. Finally, parental reports of childhood $\mathrm{HI}$ were strongly associated with $\mathrm{T} 0 \mathrm{HI}$, suggesting validity in the sense that adolescent HI was continuous with earlier permanent or recurrent $\mathrm{HI}$. In addition, the validity of the findings was supported by the fact that if exposure status was restricted to those participants with $\mathrm{HI}$ who also had evidence of childhood HI according to parental report, the OR was also very high, albeit statistically inconclusive due to the small number of participants. Furthermore, to the degree that misclassification may have arisen, it is difficult to see how this could have been differential with regard to the psychosis outcome.

Second, the assessment of psychotic experiences confers the risk of false-positive answers, increasing 
random error. However, not only was the DIA-X/MCIDI specifically developed for use in young and adolescent populations, there is also a substantial literature on the validity of self-reported psychotic experiences (van Os et al. 2009). In addition, the assessment of psychotic experiences in the current study was based on both self-report and diagnostic interview by trained and experienced clinical psychologists, lowering the risk for false-positive ratings.

Finally, although observational studies cannot provide evidence for causality in the association between $\mathrm{HI}$ and psychotic symptoms, no evidence to date exists to support reverse causality (psychosis provoking spurious reports of having impaired hearing). Furthermore, the association remained highly significant after exclusion of those people at baseline with high psychosis scores, rendering reverse causality as an explanation for the findings less likely.

\section{Acknowledgements}

This work is part of the Early Developmental Stages of Psychopathology (EDSP) Study. The EDSP Study is funded by the German Federal Ministry of Education and Research (BMBF; project no. 01EB9405/6, no. 01EB 9901/6, no. EB01016200, no. 01EB0140 and no. 01EB0440). Part of the field work and analyses were also additionally supported by grants of the Deutsche Forschungsgemeinschaft (DFG; project no. LA1148/1-1, no. WI2246/1-1, no. WI 709/7-1 and no. WI 709/8-1).

The principal investigators of the EDSP Study were H.W. and R.L. The core staff members of the EDSP group were: Dr Katja Beesdo, Dr Petra Zimmermann, Dr Axel Perkonigg, Dr Michael Höfler, Dr Tanja Brückl, Agnes Nocon, Hildegard Pfister, Barbara Spiegel and Dr Andrea Schreier. Scientific advisors are Dr Jules Angst (Zurich), Dr Kathleen Merikangas (National Institute of Mental Health, Bethesda), Dr Ron Kessler (Harvard, Boston) and J.v.O. (Maastricht). The EDSP project and its family genetic supplement have been approved by the Ethics Committee of the Faculty of the Technische Universität Dresden (no. EK-13811). All participants provided informed consent.

\section{Declaration of Interest}

R.L. has received speaker honoraria from Wyeth. H.W. has received research support from Novartis, Pfizer and Schering-Plough, has been a consultant for Novartis, Pfizer, Wyeth, Organon and Lundbek, and has received speaker honoraria from Novartis, Schering-Plough, Pfizer, Wyeth and Servier. J.v.O. is/has been an unrestricted research grant holder with, or has received financial compensation as an independent symposium speaker from, Eli Lilly, BMS, Lundbeck, Organon, Janssen-Cilag, GSK, AstraZeneca, Pfizer and Servier - companies that have an interest in the treatment of psychosis.

\section{References}

Arrindell WA, Ettema JHM (eds) (2003). SCL-90. Handleiding bij een Multidimensionale Psychopathologie Indicator [SCL-90. Manual of a Multidimensional Indicator of Psychopathology]. Swets Test Publisher: Lisse.

Bentall RP (1990). The illusion of reality: a review and integration of psychological research on hallucinations. Psychological Bulletin 107, 82-95.

Bess FH, Dodd-Murphy J, Parker RA (1998). Children with minimal sensorineural hearing loss: prevalence, educational performance, and functional status. Ear and Hearing 19, 339-354.

Bonicatto S, Dew MA, Soria JJ, Seghezzo ME (1997). Validity and reliability of Symptom Checklist '90 (SCL90) in an Argentine population sample. Social Psychiatry and Psychiatric Epidemiology 32, 332-338.

Boydell J, van Os J, McKenzie K, Murray RM (2004). The association of inequality with the incidence of schizophrenia - an ecological study. Social Psychiatry and Psychiatric Epidemiology 39, 597-599.

Brown AS, Cohen P, Greenwald S, Susser E (2000). Nonaffective psychosis after prenatal exposure to rubella. American Journal of Psychiatry 157, 438-443.

Cannon M, Caspi A, Moffitt TE, Harrington H, Taylor A, Murray RM, Poulton R (2002). Evidence for earlychildhood, pan-developmental impairment specific to schizophreniform disorder: results from a longitudinal birth cohort. Archives of General Psychiatry 59, 449-456.

Chapman LJ, Chapman JP, Kwapil TR, Eckblad M, Zinser MC (1994). Putatively psychosis-prone subjects 10 years later. Journal of Abnormal Psychology 103, 171-183.

Cooper AF, Curry AR (1976). The pathology of deafness in the paranoid and affective psychoses of later life. Journal of Psychosomatic Research 20, 97-105.

Cougnard A, Marcelis M, Myin-Germeys I, De Graaf R, Vollebergh W, Krabbendam L, Lieb R, Wittchen HU, Henquet C, Spauwen J, Van Os J (2007). Does normal developmental expression of psychosis combine with environmental risk to cause persistence of psychosis? A psychosis proneness-persistence model. Psychological Medicine 37, 513-527.

Dalman C, Allebeck P, Gunnell D, Harrison G, Kristensson K, Lewis G, Lofving S, Rasmussen F, Wicks S, Karlsson H (2008). Infections in the CNS during childhood and the risk of subsequent psychotic illness: a cohort study of more than one million Swedish subjects. American Journal of Psychiatry 165, 59-65.

David A, Malmberg A, Lewis G, Brandt L, Allebeck P (1995). Are there neurological and sensory risk factors for schizophrenia? Schizophrenia Research 14, 247-251.

Derogatis LR (1983). SCL-90-R Administration, Scoring and Procedures Manual-II. Clinical Psychometric Research: Towson, MD 
Dominguez MD, Wichers M, Lieb R, Wittchen HU, van Os J (2009). Evidence that onset of clinical psychosis is an outcome of progressively more persistent subclinical psychotic experiences: an 8-year cohort study. Schizophrenia Bulletin. Published online: 21 May 2009. doi: $10.1093 /$ schbul/sbp022.

Fortnum H, Davis A (1993). Hearing impairment in children after bacterial meningitis: incidence and resource implications. British Journal of Audiology 27, 43-52.

Frith CD (1992). The Cognitive Neuropsychology of Schizophrenia. Lawrence Erlbaum Associates: Hove, UK.

Hanssen M, Bak M, Bij1 R, Vollebergh W, van Os J (2005). The incidence and outcome of subclinical psychotic experiences in the general population. British Journal of Clinical Psychology 44, 181-191.

Henquet C, Krabbendam L, Spauwen J, Kaplan C, Lieb R, Wittchen HU, van Os J (2005). Prospective cohort study of cannabis use, predisposition for psychosis, and psychotic symptoms in young people. British Medical Journal (Clinical Research Edition) 330, 11.

Herrgard E, Karjalainen S, Martikainen A, Heinonen K (1995). Hearing loss at the age of 5 years of children born preterm - a matter of definition. Acta Paediatrica 84, 1160-1164.

Janssen I, Krabbendam L, Jolles J, van Os J (2003). Alterations in theory of mind in patients with schizophrenia and non-psychotic relatives. Acta Psychiatrica Scandinavica 108, 110-117.

Kapur S, Mizrahi R, Li M (2005). From dopamine to salience to psychosis - linking biology, pharmacology and phenomenology of psychosis. Schizophrenia Research 79, 59-68.

Kaymaz N, van Os J (2010). Extended psychosis phenotype - yes: single continuum - unlikely. Psychological Medicine. Published online: 20 March 2010. doi : 10.1017/S0033291710000358.

Kramer SE, Kapteyn TS, Kuik DJ, Deeg DJ (2002). The association of hearing impairment and chronic diseases with psychosocial health status in older age. Journal of Aging and Health 14, 122-137.

Lataster T, Myin-Germeys I, Derom C, Thiery E, van Os J (2009). Evidence that self-reported psychotic experiences represent the transitory developmental expression of genetic liability to psychosis in the general population. American Journal of Medical Genetics Part B 150B, 1078-1084.

Leask SJ, Done DJ, Crow TJ (2002). Adult psychosis, common childhood infections and neurological soft signs in a national birth cohort. British Journal of Psychiatry 181, 387-392.

Leff JP (1968). Perceptual phenomena and personality in sensory deprivation. British Journal of Psychiatry 114, 1499-1508.

Lieb R, Isensee B, von Sydow K, Wittchen HU (2000). The Early Developmental Stages of Psychopathology Study (EDSP): a methodological update. European Addiction Research 6, 170-182.

Linscott RJ, van Os J (2010). Systematic reviews of categorical versus continuum models in psychosis: evidence for discontinuous subpopulations underlying a psychometric continuum. Implications for DSM-V,
DSM-VI, and DSM-VII. Annual Review of Clinical Psychology 6, 391-419.

Marschark M (1993). Psychological Development of Deaf Children. Oxford University Press : New York.

Mason OJ, Brady F (2009). The psychotomimetic effects of short-term sensory deprivation. Journal of Nervous and Mental Disease 197, 783-785.

Olusanya BO, Newton VE (2007). Global burden of childhood hearing impairment and disease control priorities for developing countries. Lancet 369, 1314-1317.

Paykel ES, Abbott R, Jenkins R, Brugha TS, Meltzer H (2000). Urban-rural mental health differences in Great Britain: findings from the National Morbidity Survey. Psychological Medicine 30, 269-280.

Peters ER, Joseph SA, Garety PA (1999). Measurement of delusional ideation in the normal population: introducing the PDI (Peters et al. Delusions Inventory). Schizophrenia Bulletin 25, 553-576.

Peterson CC, Siegal M (1995). Deafness, conversation and theory of mind. Journal of Child Psychology and Psychiatry 36, 459-474.

Peterson CC, Siegal M (1998). Changing focus on the representational mind: deaf, autistic and normal children's concept of false photos, false drawings and false beliefs. British Journal of Developmental Psychology 16, 301-320.

Peterson CC, Wellman HM, Liu D (2005). Steps in theoryof-mind development for children with deafness or autism. Child Development 76, 502-517.

Poulton R, Caspi A, Moffitt TE, Cannon M, Murray R, Harrington $\mathbf{H}$ (2000). Children's self-reported psychotic symptoms and adult schizophreniform disorder: a 15-year longitudinal study. Archives of General Psychiatry 57, 1053-1058.

Reed V, Gander F, Pfister H, Steiger A, Sontagg H, Trenkwalder C, Hundt W, Wittchen H (1998). To what degree does the Composite International Diagnostic Interview (CIDI) correctly identify DSM-IV disorders? Testing validity issues in a clinical sample. International Journal of Methods in Psychiatric Research 7, 619-627.

Romans-Clarkson SE, Walton VA, Herbison GP, Mullen PE (1990). Psychiatric morbidity among women in urban and rural New Zealand: psycho-social correlates. British Journal of Psychiatry 156, 84-91.

Rossler W, Riecher-Rossler A, Angst J, Murray R, Gamma A, Eich D, van Os J, Gross VA (2007). Psychotic experiences in the general population: a twenty-year prospective community study. Schizophrenia Research 92, $1-14$.

Russell PA, Hosie JA, Gray CD, Scott C, Hunter N, Banks JS, Macaulay MC (1998). The development of theory of mind in deaf children. Journal of Child Psychology and Psychiatry 39, 903-910.

Schultz G, Melzack R (1991). The Charles Bonnet syndrome: 'phantom visual images'. Perception 20, 809-825.

Selten JP, Cantor-Graae E (2007). Hypothesis: social defeat is a risk factor for schizophrenia? British Journal of Psychiatry 51 (Suppl.), s9-s12.

Sindhusake D, Mitchell P, Smith W, Golding M, Newall P, Hartley D, Rubin G (2001). Validation of self-reported 
hearing loss. The Blue Mountains Hearing Study. International Journal of Epidemiology 30, 1371-1378.

Spauwen J, Krabbendam L, Lieb R, Wittchen HU, van Os J (2006). Evidence that the outcome of developmental expression of psychosis is worse for adolescents growing up in an urban environment. Psychological Medicine 36, 407-415.

Stefanis N, Thewissen V, Bakoula C, van Os J, Myin-Germeys I (2006). Hearing impairment and psychosis: a replication in a cohort of young adults. Schizophrenia Research 85, 266-272.

Stein LM, Thienhaus OJ (1993). Hearing impairment and psychosis. International Psychogeriatrics 5, 49-56.

Tharpe AM, Sladen DP (2008). Causation of permanent unilateral and mild bilateral hearing loss in children. Trends in Amplification 12, 17-25.

Thewissen V, Myin-Germeys I, Bentall R, de Graaf R, Vollebergh W, van Os J (2005). Hearing impairment and psychosis revisited. Schizophrenia Research 76, 99-103.

van der Werf M, van Boxtel M, Verhey F, Jolles J, Thewissen V, van Os J (2007). Mild hearing impairment and psychotic experiences in a normal aging population. Schizophrenia Research 94, 180-186.

van Os J, Linscott RJ, Myin-Germeys I, Delespaul P, Krabbendam L (2009). A systematic review and meta-analysis of the psychosis continuum: evidence for a psychosis proneness-persistence-impairment model of psychotic disorder. Psychological Medicine 39, 179-195.

van Os J, Rutten BP, Poulton R (2008). Gene-environment interactions in schizophrenia: review of epidemiological findings and future directions. Schizophrenia Bulletin 34, 1066-1082.

van Winkel R, Stefanis NC, Myin-Germeys I (2008). Psychosocial stress and psychosis. A review of the neurobiological mechanisms and the evidence for gene-stress interaction. Schizophrenia Bulletin 34 1095-1105.

Veling W, Selten JP, Susser E, Laan W, Mackenbach JP, Hoek HW (2007). Discrimination and the incidence of psychotic disorders among ethnic minorities in The Netherlands. International Journal of Epidemiology 36, 761-768.

Verdoux H, Maurice-Tison S, Gay B, Van Os J, Salamon R, Bourgeois ML (1998). A survey of delusional ideation in primary-care patients. Psychological Medicine 28, 127-134.

Weiser M, Werbeloff N, Drukker M, Van Os J, Dohrenwend BP, Yoffe R, Levav I, Davidson M (2009).

Self-reported psychotic symptoms in the community, and risk of later hospitalization for non-affective psychotic disorders. Schizophrenia Bulletin 35, 74.

Welham J, Scott J, Williams G, Najman J, Bor W, O'Callaghan M, McGrath J (2009). Emotional and behavioural antecedents of young adults who screen positive for non-affective psychosis: a 21-year birth cohort study. Psychological Medicine 39, 625-634.

WHO (1990). Composite International Diagnostic Interview (CIDI), Version 1.0. World Health Organisation: Geneva, Switzerland.

Wittchen H, Pfister H (eds) (1997). DIA-X-Interviews: Manual für Screening-Verfahren und Interview; Interviewheft Längsschnittuntersuchung (DIA-X-Lifetime); Engänzungsheft (DIA-X-Lifetime); Interviewheft Querschnittsuntersuchung (DIA-X-Monatsversion); Ergänzungsheft (DIA-X-12 Monatsversion); PC-programm zur Durchfuhrung der Interviews (Längs und Querschnittsuntersuchung); Ausertungsprogramm [DIA-X-Interviews: Manual for Screening and Interview, Interview Issue Longitudinal Study (DIA-X-Lifetime), Supplement Issue (DIA-X-Lifetime); Interview Issue Cross-section Analysis (DIA-X-month version), Supplement Issue (DIA-X-12-month version), PC Program for Carrying out the Interviews (Longitudinal and Cross-examination); Analysis programme]. Swets \& Zeiltinger: Frankfurt, Germany.

Wittchen HU (1994). Reliability and validity studies of the WHO - Composite International Diagnostic Interview (CIDI) : a critical review. Journal of Psychiatric Research 28, 57-84.

Wittchen HU, Lachner G, Wunderlich U, Pfister H (1998a). Test-retest reliability of the computerized DSM-IV version of the Munich-Composite International Diagnostic Interview (M-CIDI). Social Psychiatry and Psychiatric Epidemiology 33, 568-578.

Wittchen H-U, Lieb R, Schuster P, Oldehinkel T (1999). When is onset? Investigations into early developmental stages of anxiety and depressive disorders. In Childhood Onset of 'Adult' Psychopathology, Clinical and Research Advances (ed. J. L. Rapoport), pp. 259-302. American Psychiatric Press: Washington.

Wittchen HU, Perkonigg A, Lachner G, Nelson CB (1998b). Early Developmental Stages of Psychopathology Study (EDSP): objectives and design. European Addiction Research $4,18-27$.

Zammit S, Odd D, Horwood J, Thompson A, Thomas K, Menezes P, Gunnell D, Hollis C, Wolke D, Lewis G, Harrison $G$ (2009). Investigating whether adverse prenatal and perinatal events are associated with non-clinical psychotic symptoms at age 12 years in the ALSPAC birth cohort. Psychological Medicine 39, 1457-1467. 